\title{
Semaphorin 3E-Plexin-D1 signaling regulates VEGF function in developmental angiogenesis via a feedback mechanism
}

\author{
Jiha Kim, ${ }^{1,4}$ Won-Jong Oh, ${ }^{1,4}$ Nicholas Gaiano, ${ }^{2}$ Yutaka Yoshida, ${ }^{3}$ and Chenghua Gu ${ }^{1,5}$ \\ ${ }^{1}$ Department of Neurobiology, Harvard Medical School, Boston, Massachusetts 02115, USA; ${ }^{2}$ Department of Neurology, \\ Neuroscience, and Oncology, Institute for Cell Engineering, Johns Hopkins University, Baltimore, Maryland 21205, USA; \\ ${ }^{3}$ Division of Developmental Biology, Cincinnati Children's Research Foundation, Cincinnati, Ohio 45229, USA
}

\begin{abstract}
Blood vessel networks are typically formed by angiogenesis, a process in which new vessels form by sprouting of endothelial cells from pre-existing vessels. This process is initiated by vascular endothelial growth factor (VEGF)mediated tip cell selection and subsequent angiogenic sprouting. Surprisingly, we found that VEGF directly controls the expression of Plexin-D1, the receptor for the traditional repulsive axon guidance cue, semaphorin $3 \mathrm{E}$ (Sema3E). Sema3E-Plexin-D1 signaling then negatively regulates the activity of the VEGF-induced Delta-like 4 (Dl14)-Notch signaling pathway, which controls the cell fate decision between tip and stalk cells. Using the mouse retina as a model system, we show that Plexin-D1 is selectively expressed in endothelial cells at the front of actively sprouting blood vessels and its expression is tightly controlled by VEGF secreted by surrounding tissues. Therefore, although the Sema3E secreted by retinal neurons is evenly distributed throughout the retina, Sema3EPlexin-D1 signaling is spatially controlled by VEGF through its regulation of Plexin-D1. Moreover, we show that gain and loss of function of Sema3E and Plexin-D1 disrupts normal Dll4 expression, Notch activity, and tip/stalk cell distribution in the retinal vasculature. Finally, the retinal vasculature of mice lacking sema3E or plexin-D1 has an uneven growing front, a less-branched vascular network, and abnormal distribution of dll4-positive cells. Lowering Notch activity in the mutant mice can reverse this defect, solidifying the observation that Dll4-Notch signaling is regulated by Sema3E-Plexin-D1 and is required for its function in vivo. Together, these data reveal a novel role of Sema3E-Plexin-D1 function in modulating angiogenesis via a VEGF-induced feedback mechanism.
\end{abstract}

[Keywords: angiogenesis; retina; VEGF; Semaphorin 3E; Plexin-D1; Notch; axon guidance]

Supplemental material is available for this article.

Received February 15, 2011; revised version accepted May 31, 2011.

Blood vessels are required to provide oxygen and nutrients to every part of the body, are essential for tissue homeostasis and repair, and also enable tumor growth. A majority of these extensive vessel networks are formed through angiogenesis, a process where new vessels form by sprouting from existing vessels (Risau 1997). This process involves the initial selection of endothelial cells called "tip cells" from the parent vessel, guidance of the new sprout, and the connection of neighboring new sprouts to augment the existing network/Gerhardt 2008; De Smet et al. 2009; Adams and Eichmann 2010; Eilken and Adams 2010). Reiteration of this tip cell selection, sprouting guidance, and connecting events is the basis for building a sophisticated vascular network. However, how molecular pathways underlying each of

\footnotetext{
${ }^{4}$ These authors contributed equally to this work.

${ }^{5}$ Corresponding author.

E-mail chenghua_gu@hms.harvard.edu.

Article is online at http://www.genesdev.org/cgi/doi/10.1101/gad.2042011.
}

these steps interact to coordinate these angiogenic processes is not clear.

The molecular mechanisms of angiogenesis rely on the critical role of vascular endothelial growth factor (VEGF). VEGF gradients within tissues are responsible for the initial triggering and guidance of the sprouting process (Ruhrberg et al. 2002; Gerhardt et al. 2003). This has been well demonstrated in the postnatal rodent retina. The retina of the mouse is avascular at birth. By the first postnatal day (P1), new vessel sprouts emerge from the central vessels at the optic nerve head and begin to elaborate into a primitive vascular network on the surface of the retina. Beginning around P6, angiogenic sprouts originating from the superficial vasculature extend vertically into the deeper retina and form two additional vascular layers (Connolly et al. 1988; Dorrell et al. 2002). It was thought that the existing network of astrocytes creates a hypoxia-dependent gradient of VEGF, which is the driving force guiding the sprouting of the superficial plexus from the center toward the periphery 
(Provis et al. 1997; Gerhardt et al. 2003; Fruttiger 2007). In situ hybridization (ISH) for vegf mRNA reveals that the highest level of VEGF expression is observed in astrocytes at the leading edge and immediately ahead of the vascular plexus, as well as in astrocytes further back in the plexus surrounding veins (Gerhardt et al. 2003). However, recent genetic studies show that astrocyte-specific deletion of either VEGF or hypoxia-inducible transcription factor (HIF) $\alpha$-isoform does not impair the normal development of the mouse retinal vasculature (Weidemann et al. 2010), suggesting that other surrounding cells such as retinal ganglion cells (RGCs) may be capable of compensating for the loss of VEGF expression in astrocytes (Stone et al. 1996). Nevertheless, the gradient of VEGF-A isoforms promotes the polarization of tip cells and the directional extension of filopodia through their interaction with the main vascular VEGF receptor, the tyrosine kinase VEGF receptor 2 (VEGFR2) (Ruhrberg et al. 2002; Gerhardt et al. 2003).

One of the key functions for VEGF is to direct tip cell selection and subsequent sprouting. During this process, only a fraction of endothelial cells acquire tip cell behavior and initiate sprouting, whereas other neighboring cells retain stalk cell identity (Gerhardt 2008; De Smet et al. 2009; Adams and Eichmann 2010). Recent studies in mice and zebrafish have demonstrated that the classical Delta-Notch lateral inhibition pathway regulates this tip cell-stalk cell decision (Roca and Adams 2007; Thurston and Kitajewski 2008; Phng and Gerhardt 2009). VEGF stimulates the expression of the Notch ligand Delta-like 4 (Dll4), which is expressed at the highest levels in tip cells (Hellstrom et al. 2007; Lobov et al. 2007; Suchting et al. 2007; Benedito et al. 2009). Dll4-mediated activation of Notch in the adjacent (stalk) cells suppresses the tip cell phenotype in these cells by down-regulating VEGF receptor expression and signaling (Hellstrom et al. 2007; Leslie et al. 2007; Lobov et al. 2007; Suchting et al. 2007; Benedito et al. 2009). This intercellular signaling between VEGF and the Dll4-Notch pathway ensures the appropriate ratio of tip and stalk cells required for proper sprouting and branching patterns. In dll4 heterozygous mutant mice, or when Dll4-Notch signaling is blocked, an excessive number of tip cells is formed and vascular density is dramatically increased (Hellstrom et al. 2007; Lobov et al. 2007; Suchting et al. 2007; Benedito et al. 2009). In contrast, when Notch is activated by its agonist, a decrease in vessel density is observed (Hellstrom et al. 2007; Lobov et al. 2007; Suchting et al. 2007; Benedito et al. 2009).

Vascular and axon guidance have both morphological and molecular similarities. All four major axon guidance cues have been shown to play a role in guiding developing blood vessels (Carmeliet and Tessier-Lavigne 2005; Gelfand et al. 2009; Adams and Eichmann 2010). Several of these molecules function as repulsive guidance cues to steer the vascular sprouts. We previously identified a ligand-receptor interaction between a traditional axon guidance cue, the secreted semaphorin $3 \mathrm{E}$ (Sema3E), and its receptor Plexin-D1 and we showed that this interaction is required for intersomitic vessel patterning during mouse development (Gu et al. 2005). We found that Sema3E is expressed in a caudal-to-rostral gradient in the somite and that this gradient serves to prevent intersomitic vessels from entering the caudal region. As a result, exuberant sprouting entering the caudal somite region is observed in sema3E (Gu et al. 2005) and plexinD1 mutants (Gitler et al. 2004; Torres-Vazquez et al. 2004; Gu et al. 2005). However, in some tissues, Sema3E does not exhibit any apparent gradient (J Kim and C Gu, unpubl.), suggesting that Sema3E-Plexin-D1 signaling has functions other than guidance. How Sema3E-Plexin-D1 signaling is integrated at the molecular level with the angiogenic process and whether it functions independently or in concert with VEGF signaling are unknown.

Here we use vascularization of the postnatal retina as a model system to examine the role of Sema3E-Plexin-D1 signaling in the VEGF-mediated angiogenic process. We found that Plexin-D1 is selectively expressed in endothelial cells at the front of actively sprouting blood vessels, and that, surprisingly, its expression is both necessary and sufficiently regulated by VEGF. Moreover, Sema3E is secreted from RGCs and is evenly distributed throughout the retina. We show that Sema3E-Plexin-D1 signaling negatively regulates Dll4 expression and Notch activity downstream from VEGF. Gain and loss of function of Sema3E and Plexin-D1 disrupt normal Dll4 distribution, Notch activity, and the tip/stalk cell ratio in the retinal vasculature. Finally, mice lacking sema3E or plexin-D1 display an uneven growing front of the retinal vasculature, a less-branched vascular network, and an abnormal distribution of Dll4-positive cells. Lowering Notch activity in the mutant mice can reverse this defect, further supporting that Dll4-Notch signaling is regulated by Sema3E-Plexin-D1 signaling and is required for its function in vivo. Together, these data reveal a new role of Sema3E-Plexin-D1 function in modulating angiogenic cell fate decision via a VEGF-induced negative feedback mechanism to ensure coordinated angiogenesis.

\section{Results}

Plexin-D1 is dynamically expressed in endothelial cells at the front of actively sprouting blood vessels and Sema3E is expressed in RGCs

To investigate the potential interactions of Sema3EPlexin-D1 signaling and VEGF function in angiogenesis, we used the mouse retinal vasculature, a model system in which VEGF function in angiogenesis has been well characterized (Uemura et al. 2006; Fruttiger 2007). We first examined Plexin-D1 expression in the retina during the first postnatal week. At P2, when vessels are just emerging from the optic disk, most of the vessels are actively sprouting and plexin-D1 is present in most endothelial cells (Fig. 1A). From P3 to P5, as the vessel sprouting continues toward the periphery of the retina, the level of plexin-D1 mRNA is down-regulated in the central part of the vascular plexus (asterisks in Fig. 1B,C,D) and is only detected in the actively sprouting vessels at the front of the network and in veins (arrows in Fig. 1B,C). By P6, plexin-D1 


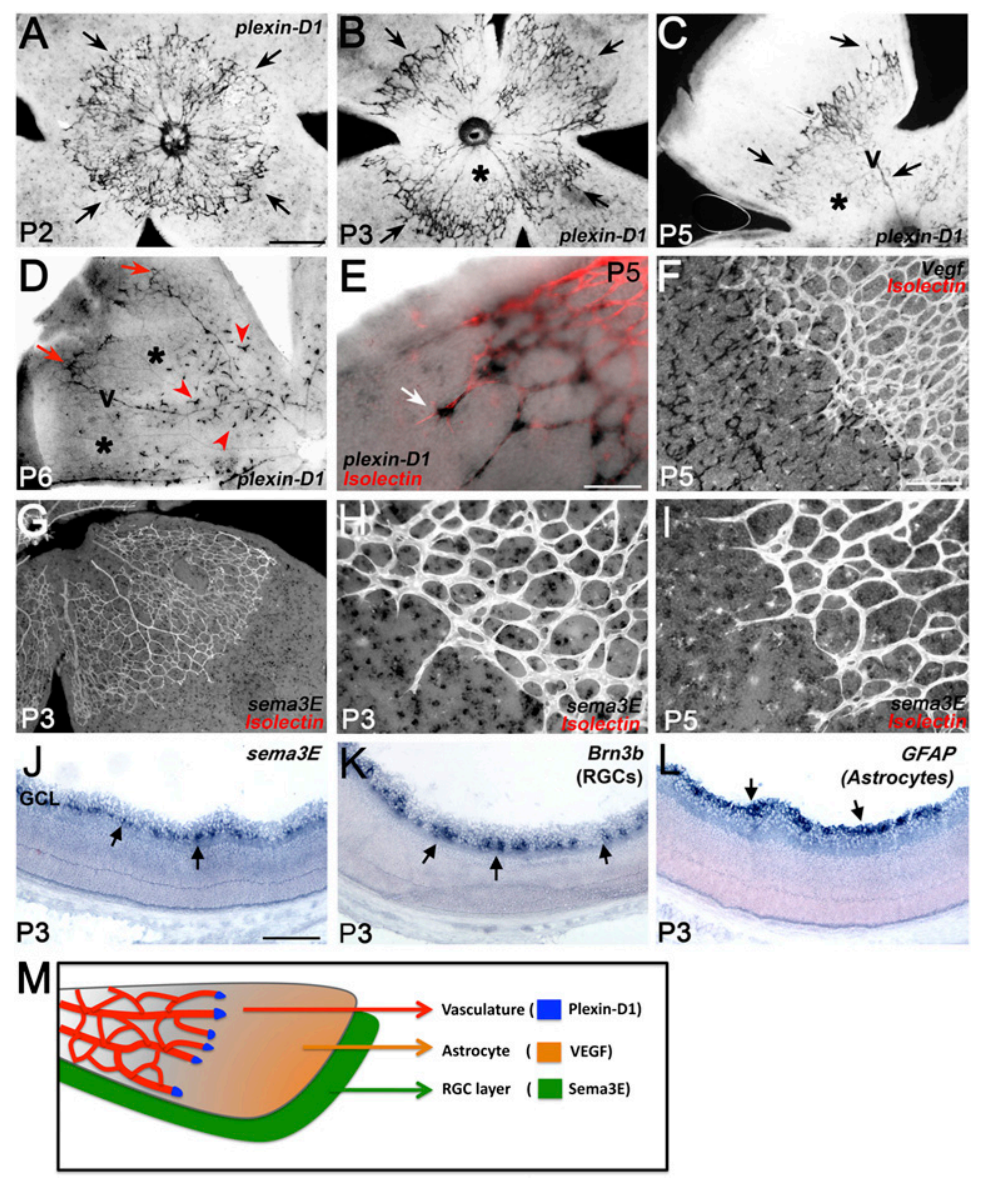

Figure 1. Plexin-D1, VEGF, and Sema3E are selectively expressed in adjacent layers of the retina and Plexin-D1 expression is dynamically regulated. $(A-E)$ plexin-D1 ISH on whole-mount retina at P2 $(A), \mathrm{P} 3(B), \mathrm{P} 5(C, E)$, and $\mathrm{P} 6(D)$ shows that plexin-D1 mRNA is predominantly expressed in actively sprouting vessels (arrows in $A-E$ ). Plexin-D1 expression is absent in the mature vessels (asterisks in $B-D$ ) and reappears in the newly formed sprouts that form deeper vascular layers at P6 (arrowheads in $D$ ). In $E$, the retina was double-stained with Isolectin B4 after plexin-D1 ISH in order to visualize the blood vessels. $(F)$ vegf ISH of P5 wholemount retina (black deposit) and costaining vessels with Isolectin B4 (white) show high vegf mRNA in cells underneath the vascular layer immediately ahead of the vascular plexus and low or no expression in areas covered by blood vessels. $(G-I)$ sema3E ISH of P3 and P5 whole-mount retinas shows even distribution of sema3E mRNA (black deposit). Vessels were visualized by staining with Isolectin $\mathrm{B} 4$ (white). (J-L) ISH on sections through $\mathrm{P} 3$ retinas shows that sema3E expression is limited to the RGC layer (arrows in $J$ ), as shown by its overlapping expression with Brn3b-expressing RGCs (arrows in $K$ ) but not with GFAP-expressing astrocytes (arrows in $L$ ). (M) Summary of the distribution of VEGF (astrocyte layer), Plexin-D1 (vasculature), and Sema3E (RGC layer). Bars: $A-D, G, 500 \mu \mathrm{m} ; F, J-L, 200 \mu \mathrm{m} ; E, H, I$, $100 \mu \mathrm{m}$.

is selectively up-regulated in the center of the plexus, at the site where vessels start to sprout downward to form the deeper vascular layers (arrowheads in Fig. 1D). Therefore, plexin-D1 expression is dynamically regulated and most prominently associated with actively growing vessels. Plexin-D1 is expressed highly in tip cells at the vascular front (arrow in Fig. 1E). The dynamic up-regulation of Plexin-D1 in tip cells suggests that it plays an important role in VEGF-mediated angiogenic sprouting. Wholemount ISH for Sema3E, one of Plexin-D1's ligands, showed that sema3E is expressed beneath the superficial plexus (Fig. 1G-I). ISH of adjacent sections through the P3 retina for sema3E and Brn3b, a marker of RGCs, and GFAP, an astrocyte marker, showed that sema3E is expressed in the Brn3b-positive layer (Fig. 1, cf. J and K), but not in the GFAP-positive layer (Fig. 1, cf. J and L). Therefore, Sema3E is expressed in RGCs. Unlike plexin$D 1$, sema3E expression was distributed evenly over the entire retina. Moreover, there was no obvious sema3E gradient along the central-peripheral axis of the developing retina, as observed for vegf (Fig. 1F).

\section{VEGF is necessary and sufficient to induce Plexin-D1 expression in angiogenic blood vessels}

The proximity to VEGF expression and the dynamic expression pattern of Plexin-D1 raise the possibility that
VEGF is responsible for the regulation of Plexin-D1 expression. To directly test this, we examined the effect of altering VEGF signaling on the expression of Plexin-D1 by injecting either VEGF or an anti-VEGFR2 antibody into the vitreous of P5 mice and examining plexin-D1 mRNA levels. As expected, plexin-D1 is expressed mainly at the front of the sprouting vessels and in the veins of control retinas injected with phosphate-buffered saline (PBS) (Fig. 2A). However, intravitreal injection of VEGF into the eye of a P5 mouse led to dramatic upregulation of plexin-D1 mRNA, especially in central vessels that normally have little or no plexin-D1 expression (Fig. 2B). Vessels also displayed a previously described shortened filopodia phenotype (Gerhardt et al. 2003). Conversely, when a neutralizing antibody against VEGFR2 was injected intravitreally, plexin-D1 expression became barely detectable (Fig. 2C) despite the continued existence of an intact vascular plexus, as demonstrated by costaining with Isolectin B4 (Fig. 2F). Therefore, VEGF is necessary and sufficient for Plexin-D1 expression in vivo. To further examine how quickly plexin-D1 expression is induced by VEGF, we performed plexin-D1 ISH at multiple time points after VEGF intravitreal injection. PlexinD1 up-regulation was observed as early as $1 \mathrm{~h}$ after VEGF injection in the P5 retina (Fig. 2I). The rapid induction of Plexin-D1 suggests that this is a direct consequence of signaling by VEGF and its receptor, VEGFR2. Therefore, 


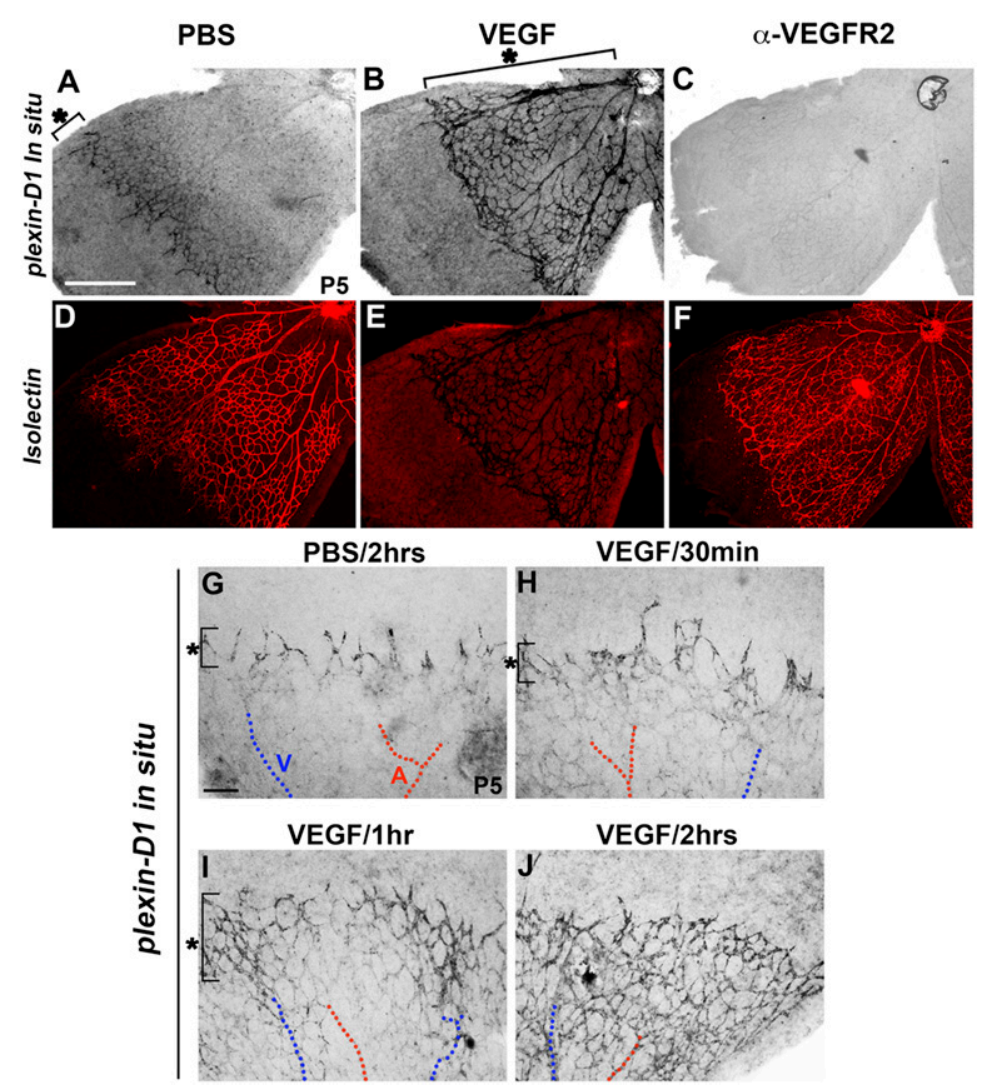

Figure 2. Plexin-D1 expression is tightly regulated by VEGF. $(A-F)$ VEGF is necessary and sufficient for PlexinD1 expression. P5 wild-type retinas were injected with PBS $(A, D)$, VEGF165 $(B, E)$, or anti-VEGFR2 antibody $(C, F)$, then fixed after $8 \mathrm{~h}$, processed for plexin-D1 ISH $(A-C)$, and finally stained with Isolectin B4 to visualize the vasculature $(D-F)$. plexin-D1 expression is greatly enhanced and expanded to all vessels after intraocular injection of VEGF (bracket in $B$ ) compared with PBS (bracket in A). plexin-D1 expression is almost absent after anti-VEGFR2 antibody injection $(C)$, although the vessels are still intact, as evidenced by Isolectin staining $(F)$. Note that the apparently weak Isolectin staining in $E$ is due to the extremely high levels of plexin-D1 ISH signal shown in $B .(G-J)$ plexin-D1 expression is rapidly induced by VEGF. P5 retinas were injected with either PBS $(G)$ or VEGF $(H-I)$; fixed after $30 \mathrm{~min}(H), 1 \mathrm{~h}(I)$, or 2 $\mathrm{h}(J)$; and processed for plexin-D1 ISH. plexin-D1 expression is noticeably enhanced and expanded in the periphery $1 \mathrm{~h}$ after VEGF injection (bracket in $I$ ), especially around veins (marked as $V$, blue lines) compared with the bracket in $G$ and $H$. Two hours after the injection of VEGF, plexin-D1 expression is greatly expanded toward the capillary plexus (shown in the center), including both veins and arteries (marked as A, red lines). The bar $(500$ $\mu \mathrm{m})$ in $A$ applies to $B-F$. The bar $(200 \mu \mathrm{m})$ in $G$ applies to $H-I$.

Plexin-D1 expression in retinal capillaries and veins is dynamically regulated by local expression of VEGF. As a result, even though Sema3E expression is evenly distributed in the developing retina, dynamic regulation of Plexin-D1 expression provides the opportunity for dynamic Sema3E-Plexin-D1 signaling in response to VEGF during retinal development.

\section{Sema3E-Plexin-D1 signaling inhibits D114 expression in retinal vasculature}

Gradient formation of secreted guidance cues has been shown to be the key principle required for directing the navigation of developing neuronal growth cones and vascular sprouts via regulation of cytoskeletal dynamics (Carmeliet and Tessier-Lavigne 2005). Therefore, the even distribution of sema3E in the RGC layer suggests that Sema3E-Plexin-D1 signaling in the retinal vasculature functions differently than it does in the intersomitic vessels, where a caudal-to-rostral Sema3E gradient limits the expansion of Plexin-D1-expressing vessels (Gu et al. 2005). Since Plexin-D1 is dynamically regulated by VEGF in endothelial cells at the front of actively sprouting vessels, we asked whether Sema3E-Plexin-D1 activation affects the Dll4 and Notch pathway, which is downstream from VEGF and plays an essential role in tip versus stalk cell fate determination (Hellstrom et al. 2007; Lobov et al. 2007; Suchting et al. 2007; Benedito et al. 2009). We examined the effect of Sema3E-Plexin-D1 signaling on the expression of Dll4 by injecting alkaline phosphatase (AP)-tagged Sema3E into the vitreous of P5 mice and examining d114 mRNA levels, with VEGF injection serving as the positive control. AP-Sema3E has full biological activity as shown previously $(\mathrm{Gu}$ et al. 2005; Chauvet et al. 2007; Casazza et al. 2010). As expected, when PBS was injected, d114 expression was only detected in tip cells. However, $5 \mathrm{~h}$ after VEGF injection, significantly more cells were found to express dll4 (Fig. 3A-C). In contrast, intravitreal injection of APSema3E led to a dramatic decrease in the level of $d 114$ and in the number of cells that express detectable dll4 compared with the control AP-injected retina (Fig. 3D-F).

In addition, we also examined whether Sema3E-PlexinD1 signaling directly regulates VEGF-induced d114 expression in human umbilical vein endothelial cells (HUVECs). Consistent with the in vivo finding, VEGF treatment increased d114 mRNA in HUVECs within 30 min. However, this effect was dramatically attenuated by treatment with Sema3E (Supplemental Fig. S1A). Moreover, down-regulation of Plexin-D1 by plexin-D1 RNAi completely abrogated this effect (Supplemental Fig. S1B). Therefore, Sema3E-Plexin-D1 signaling inhibits VEGFinduced Dll4 expression in vitro. This effect was also present in the mouse retina where intraocular injection of AP-Sema3E blocked VEGF-induced dll4 induction (Supplemental Fig. S1C-E). Taken together, these data show that Sema3E-Plexin-D1 signaling negatively regulates Dll4 expression. 


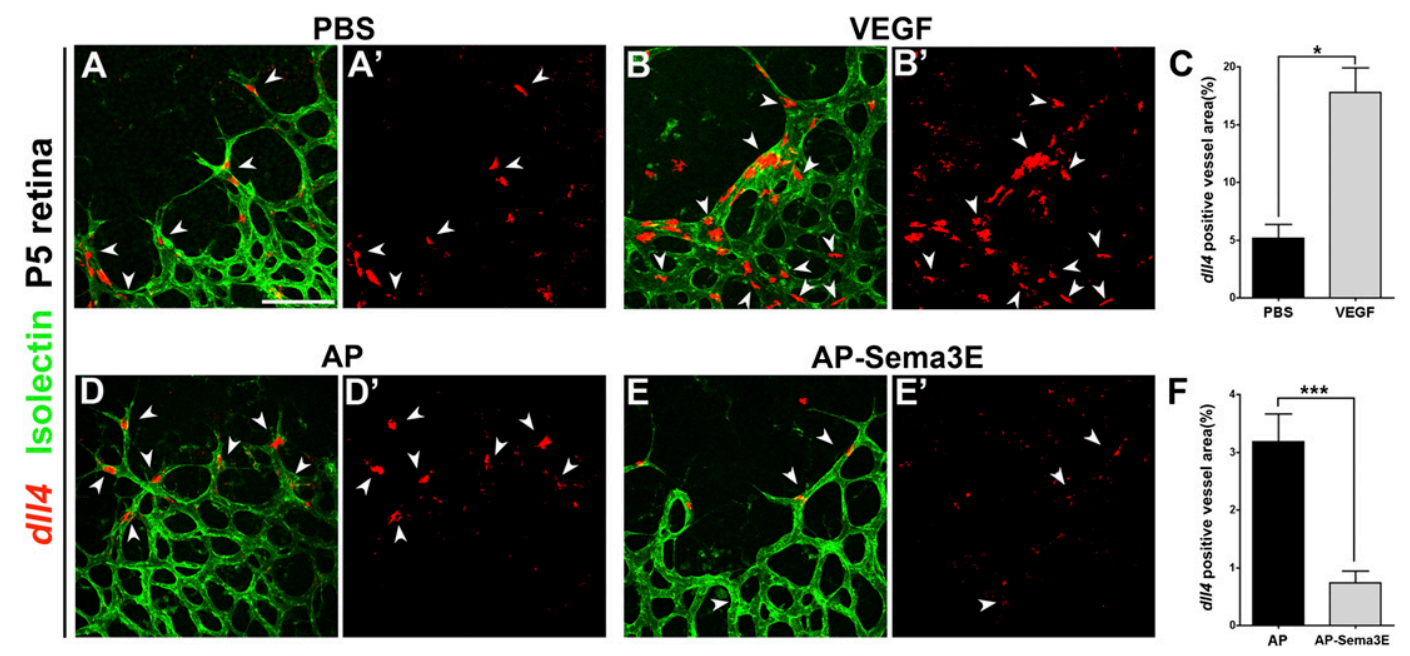

Figure 3. Activation of Sema3E-Plexin-D1 signaling suppresses dl14 expression in the retinal vasculature. dll4 expression is induced by VEGF and suppressed by Sema3E. P5 wild-type retinas were intraocularly injected with PBS $\left(A, A^{\prime}\right), 1 \mu \mathrm{g} / \mu \mathrm{L}$ VEGF $165\left(B, B^{\prime}\right), 100 \mathrm{nM}$ AP control $\left(D, D^{\prime}\right)$, or $100 \mathrm{nM}$ AP-Sema3E $\left(E, E^{\prime}\right)$. Retinas were fixed after $5 \mathrm{~h}$ and processed for $d 114 \mathrm{ISH}$ (pseudocolored red, $\left.A^{\prime}-D^{\prime}\right)$ and then double-stained with Isolectin B4 (green, $A-D) .(A-C)$ dll4 expression is induced by VEGF. Note that dll4 expression is greatly enhanced and expanded to almost all endothelial cells $5 \mathrm{~h}$ after the intraocular injection of VEGF (arrowheads in $B, B^{\prime}$ ) compared with the control PBS injection (arrowheads in $\left.A, A^{\prime}\right) .(C)$ Quantification of the dll4-positive area in PBS-injected and VEGF-injected retinas. The dll4-positive area is normalized by Isolectin B4 staining (vessel area) from individual images unless otherwise noted. $\left({ }^{*}\right) P<0.05$. PBS, $n=3$; VEGF, $n=3$. (n) Number of animals unless otherwise noted. $(D-F)$ dll4 expression is suppressed by Sema3E. Note that $d 114$ expression is dramatically reduced in endothelial tip cells $5 \mathrm{~h}$ after intraocular injection of AP-Sema3E (arrowheads in $E, E^{\prime}$ ) compared with control AP injection (arrowheads in $\left.D, D^{\prime}\right) .(F)$ Quantification of the dll4-positive area in AP-injected and AP-Sema3E-injected retinas. The dll4-positive area is normalized by the Isolectin B4-stained vessel area. $A^{\prime}, B^{\prime}, D^{\prime}$, and $E^{\prime}$ are dll4 ISH single-labeled images to allow clear visualization of $d 114$ expression. $\left({ }^{* * *}\right) P<0.0001$. AP, $n=7$; Sema3E, $n=7$. The bar $(100 \mu \mathrm{m})$ in $A$ applies to $B, D$, and $E$.

Loss of Sema3E-Plexin-D1 signaling increases Dll4 expression and Notch activity in the retinal vasculature

To further investigate the effect of Sema3E-Plexin-D1 signaling on Dll4 expression and Notch activity in the retina, we examined dll4 expression when Sema3EPlexin-D1 signaling was absent. First, compared with wild-type littermates, sema3E-null mice had a significant increase in the percentage of endothelial cells at the periphery of retinal vasculature that expressed dll4 (Fig. 4A-C). In addition, intravitreal injection of Plexin-D1-Fc, which neutralizes endogenous Sema3E (Supplemental Fig. S2), led to a significant increase in dll4-positive cells compared with the vehicle-injected controls (Supplemental Fig. S3). These loss-of-function results are consistent with the gain-of-function results (Fig. 3D-F), and together these data demonstrate that Sema3E-Plexin-D1 signaling negatively regulates Dll4 expression.

Dll4 signals through its receptor, Notch, which is expressed in neighboring cells, and this increase in Notch activity prevents the neighboring cell from becoming a tip cell (Hellstrom et al. 2007; Lobov et al. 2007; Suchting et al. 2007; Benedito et al. 2009). We next examined Notch signaling response in the absence of Sema3E-Plexin-D1 signaling. We performed a loss-of-function experiment in which we intravitreally injected Plexin-D1-Fc into P5 transgenic Notch reporter (TNR) mice, which carry a CBF-1 response element and a minimal SV40 promoter followed by an enhanced green fluorescent protein (GFP) sequence (Duncan et al. 2005). GFP is normally distributed in a mosaic expression pattern at the sprouting front (Hellstrom et al. 2007). Five hours after Plexin-D1Fc injection, GFP is dramatically increased compared with control retinas (Fig. 4D-F), indicating that the lack of Sema3E-Plexin-D1 signaling results in an increase of Notch signaling in retinal endothelial cells. Together, these data suggest that in the retina, Sema3E-Plexin-D1 signaling negatively regulates the level of Dll4 and, subsequently, the activity of Notch.

Our data thus far suggest a model in which VEGF induces Plexin-D1 expression in endothelial cells located in actively sprouting vessels, and as the level of Plexin-D1 rises in tip cells, Sema3E-Plexin-D1 signaling down-regulates VEGF-induced Dll4 expression and, subsequently, Notch activity in the neighboring cells (Fig. 7, below). Since Notch negatively regulates VEGFR2 in stalk cells (Lobov et al. 2007), a decrease in Notch activity would lead to an increase in VEGFR2, thus increasing Plexin-D1 expression. Consistent with this model, $5 \mathrm{~h}$ after Sema3E injection, plexin-D1 expression was greatly expanded into the vascular plexus compared with control injection (Supplemental Fig. S4A,B). Importantly, this Sema3E-induced ectopic plexin-D1 expression in stalk cells was completely blocked by injecting anti-VEGFR2 antibody (Supplemental Fig. S4E), indicating that plexin-D1 induction in stalk cells is mediated by VEGFR2. Moreover, this Sema3E-induced plexin-D1 expression was attenuated 

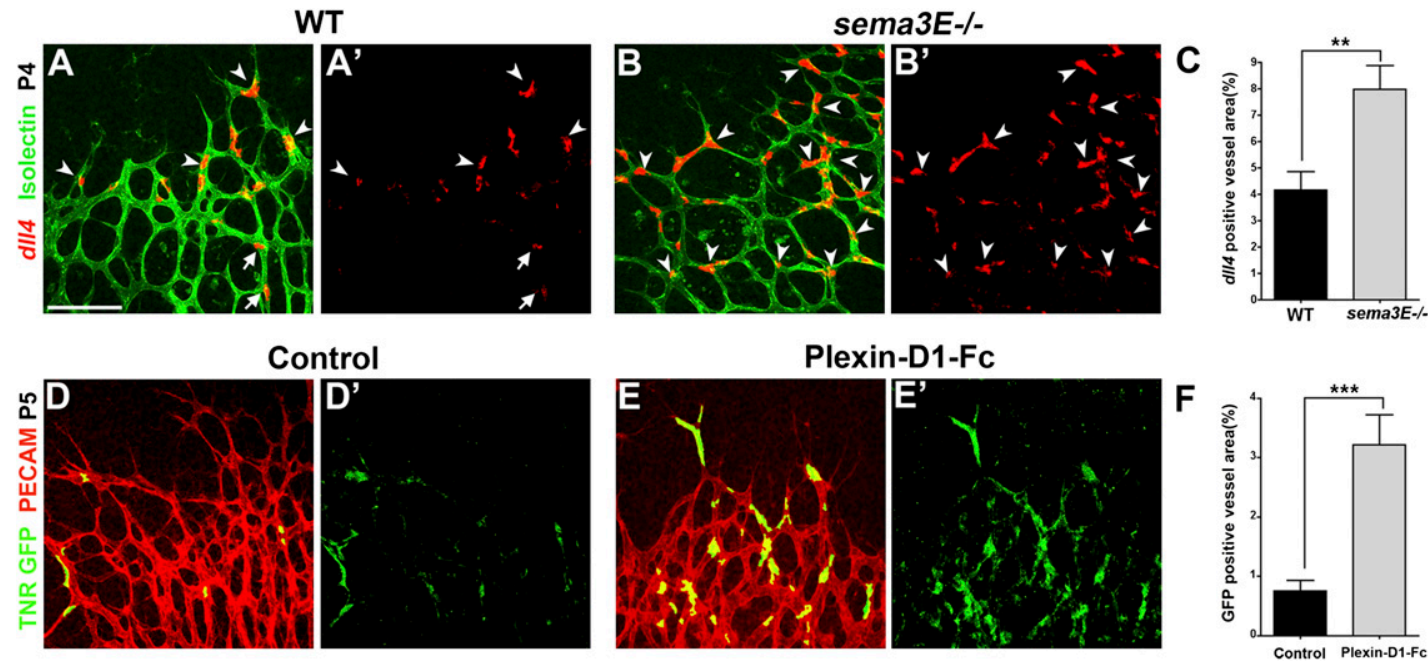

Figure 4. Blocking Sema3E-Plexin-D1 signaling induces dll4 expression and Notch activity in retinal vasculature. $(A-C)$ dll4 expression is broadly induced at the periphery of the retinal vasculature in sema3 $E^{-/}$mice. dll4 ISH (pseudocolored red) was performed on P4 wild-type littermates $\left(A^{\prime}\right)$ and $\operatorname{sema} E^{-/-}\left(B^{\prime}\right)$ retinas and then double-stained with Isolectin $\mathrm{B} 4$ (green in $\left.A, B\right)$. The percentage of $d 114$-positive area is significantly increased in sema $3 E^{-1-}$ retinas (arrowheads in $B, B^{\prime}$ ) compared with wild-type littermate retinas, in which dll4 expression is restricted to the sprouting tip cells (arrowheads in $A, A^{\prime}$ ) and endothelial cells in arteries (arrows in $A, A^{\prime}$ ). $A^{\prime}$ and $B^{\prime}$ are $d 114$ ISH single-labeled images to allow clear visualization of d114 expression. (C) Quantification of the percentage of the dll4-positive area, normalized by the Isolectin B4-positive vessel area, in sema3E $E^{-/}$retinas. $\left(^{* *}\right) P<0.005$. Wild type, $n=5$; sema3E $E^{-/-}, n=5$. $(D-F)$ Notch activity is induced by injecting Plexin-D1-Fc, which blocks endogenous Sema3E function. Notch activity is reflected by the TNR mice carrying GFP (TNR1 GFP) (Duncan et al. 2005). P5 TNR1 GFP pups were intraocularly injected with $0.2 \mu \mathrm{g} / \mu \mathrm{L}$ Plexin-D1-Fc. Retinas were fixed $5 \mathrm{~h}$ after injection and stained for both GFP (green, activated Notch) and PECAM (red, blood vessel). Notch reporter activity in blood vessels was increased throughout the periphery of the retinal vasculature after PlexinD1-Fc treatment $\left(E, E^{\prime}\right)$ compared with the control retina, in which only a few scattered GFP-positive endothelial cells can be seen $\left(D, D^{\prime}\right) . D^{\prime}$ and $E^{\prime}$ are TNR GFP single-labeled images to allow visualization of reporter activation. (F) Quantification of Notch reporter activity changes. $\left(^{* * *}\right) P<0.001$. Control, $n=4$; Plexin-D1-Fc, $n=4$. The bar $(100 \mu \mathrm{m})$ in $A$ applies to $B, D$, and $E$.

when a peptide of the Notch agonist Jag-1 was injected compared with samples intraocularly injected with scrambled peptide (scJag-1) (Supplemental Fig. S4F-H). This indicates that Sema3E-induced Plexin-D1 expression results from Sema3E-induced suppression of Notch activity. Consistent with this result, inhibiting Notch signaling by DAPT $\{\mathrm{N}-[\mathrm{N}$ - 3 , 5-difluorophenacetyl)-L-alanyl]-s-phenylglycine t-butylester\} treatment resulted in a dramatic increase in plexin-D1 expression (Supplemental Fig. S5). Together, these results further confirm the reciprocal signaling between the VEGF and Sema3EPlexin-D1 pathways (Fig. 7, below).

\section{Sema3E and Plexin-D1 are required in vivo for a balanced ratio of tip and stalk cells}

Since the Dll4-Notch lateral inhibition pathway plays a key role in balancing the tip-stalk cell ratio, through this negative feedback regulatory function, Sema3E-Plexin-D1 signaling could restrict Dll4 signaling downstream from VEGF to fine-tune the balance between tip and stalk cells during angiogenesis. We next examined whether the changes in Dll4 expression and Notch activity in the gain and loss of function of Sema3E-Plexin-D1 signaling (Figs. 3, 4) resulted in changes in the formation of tip cells in the retina vasculature. The tip cell marker angiopoietin-2 (agnpt2) was used to visualize tip cell distribution in the retinal vasculature of wild-type and mutant mice. In order to minimize variation in phenotype between different animals, we stained one retina for d114 ISH (Supplemental Fig. S6A,B,E) and the other retina from the same animal for angpt2 ISH (Supplemental Fig. S6C,D,F). In the wildtype littermate retinal vasculature, agnpt2 expression was detected specifically in tip cells in a salt-and-pepper pattern, as shown previously (del Toro et al. 2010; Strasser et al. 2010). In sema3E $E^{-/-}$mutant retinas, where dll4 expression was greatly increased (Fig. 4A-C; Supplemental Fig. S6B), we observed a significantly decreased number of endothelial cells that expressed angpt2 (Supplemental Fig. S6D). Similar changes were observed when tip cells were quantified based on their morphology (Supplemental Fig. S7A). Conversely, $5 \mathrm{~h}$ of treatment with AP-Sema3E led to down-regulation of dll4 expression (Fig. 3D-F), but the frequency of endothelial cells expressing angpt2 was significantly increased and the expression level of angpt2 was also increased (Supplemental Fig. S6H). Therefore, higher levels of Notch activity in the absence of Sema3EPlexin-D1 signaling seem to inhibit tip cell formation and result in a reduced number of agnpt2-positive cells.

\section{Sema3E and Plexin-D1 are required in vivo for coordinated retinal vascular sprouting and network formation}

To determine whether the dynamic regulation of PlexinD1 by VEGF and Sema3E-Plexin-D1 regulation of Dll4 

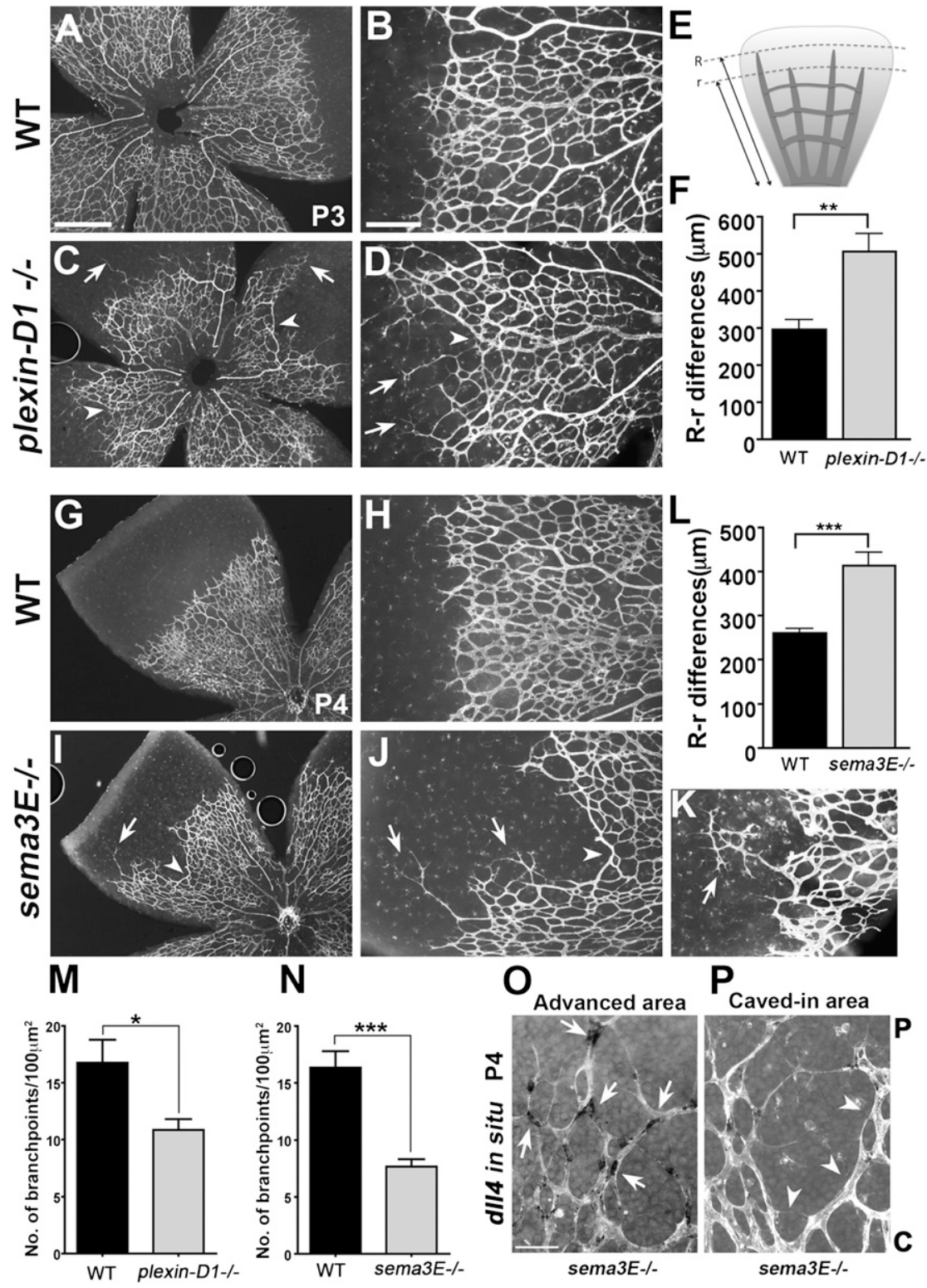

WT sema3E

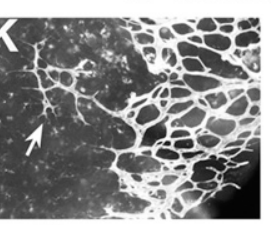

$\mathbf{P}$
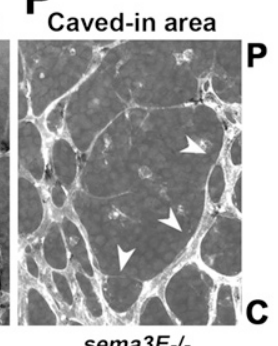

Figure 5. Lack of sema3E or plexin-D1 in mice disrupts the pattern of retinal vascular sprouting, resulting in an uneven growing front and a less-branched network. $(A-D, G-$ $K)$ Uneven growing fronts in plexin- $D 1^{-/-}$ and sema $3 E^{-1-}$ retinas. Isolectin B4 staining of whole-mount retinas from plexin- $D 1^{-/}$ $(C, D)$ pups and wild-type littermates $(A, B)$ at $\mathrm{P} 3$, and sema3 $E^{-/-}(I-K)$ pups and wild-type littermates $(G, H)$ at $\mathrm{P} 4$. Isolectin B4 staining was also performed on tamoxifen-induced plexin-D1 conditional knockout mice (plexin-D $\left.1^{\text {mut }}\right)$ and their littermate controls (see Supplemental Fig. S4). In plexin-D $1^{-1-}$ and sema3E $E^{-/-}$retinas, vessel outgrowth was uneven, with an advanced sprouting front in one area (arrows in $C, D, I-K$ ) and unusually short sprouts in its immediate neighboring area (arrowheads in $C, D, I-K)$. $(E, F, L)$ Quantification of the unevenness of the vascular front. $(E)$ Differences between the longest $(\mathrm{R})$ and shortest $(\mathrm{r})$ radius of vessels were measured in control and mutant retinas. Six to eight retinas per group were measured and the mean differences of radial expansion are shown (in microns) \pm SEM. $(F)$ Wild-type control littermate and plexin- $D 1^{-/-}$mutant retinas had $300-\mu \mathrm{m}$ and $500-\mu \mathrm{m}$ differences, respectively. $(L)$ Wild-type control and sema3 $E^{-1-}$ mutant retinas had $250-\mu \mathrm{m}$ and $400-\mu \mathrm{m}$ differences, respectively. $\left.\left({ }^{* *}\right) P<0.001 ;{ }^{* * *}\right) P<0.001$. Bar in $A(500 \mu \mathrm{m})$ applies to $C, G$, and $I$. The bar in $B(200 \mu \mathrm{m})$ applies to $D, H, J$, and $K$. $(M-N)$ Decreased vessel density in plexin$D 1^{-/-}$and $s e m a 3 E^{-/-}$retinas. Vessel density was quantified by measuring the branching points per $100 \mu \mathrm{m}^{2}$ in the peripheral area of the retinas. Vessel density was decreased in both plexin-D1-/- $(M)$ and sema3E $E^{-/-}(N)$ mice compared with their wild-type littermates. $\left({ }^{*}\right) P<0.05$; $\left.{ }^{* * *}\right) P<0.0001$. $(O, P)$ dll4 expression is highly enriched in the sprouts that grow far ahead and barely detectable in the neighboring "caved-in" area. Retinas from P4 sema3E $E^{-/-}$mice were stained for $d 114$ whole-mount ISH (black deposits) followed by Isolectin B4 staining (white). Sprouts in the advanced area contained a high frequency of dll4-positive cells (arrows in O), whereas the caved region showed little or no dll4 expression (arrowheads in $P$ ). (P) Periphery of the vascular network; $(\mathrm{C})$ center of the vascular network. The bar in $O(50 \mu \mathrm{m})$ applies to $P$.

and Notch reflect an in vivo role of Sema3E-Plexin-D1 in VEGF-mediated angiogenesis, we examined retinal vasculature in mice lacking Sema3E or Plexin-D1. Unlike its previously described graded expression in the somite, Sema3E is expressed evenly throughout the retina. Therefore, a lack of Sema3E-Plexin-D1 in vivo in the retina may not result in a synchronized exuberant sprouting phenotype, as seen in the intersomitic vessels (Gu et al. 2005). Instead, it should reflect the consequence of losing temporal and spatial control of Dll4 and Notch signaling, leading to uncoordinated angiogenesis. Most plexin-D1null mice die at birth due to cardiac defects (Gitler et al. 2004; Gu et al. 2005), but a small number can survive to P3 in an outbred strain without apparent growth retarda- tion (Supplemental Fig. S8). Using mice from this strain, we performed whole-mount Isolectin B4 staining to visualize the retinal vasculature using wild-type littermates as controls. As shown in Figure $5(A, B, G, H)$, the growing front of the developing retinal vascular plexus in wild-type littermates is evenly distributed along the vascular circumference and has staggered sprouts, with a small distance between the longest sprouts and the shortest sprouts (Fig. 5E,F,L). In contrast, in plexin-D1-null and sema3E-null mice, the growing vascular front is strikingly uneven: Some sprouts grow very far ahead of the advancing plexus (arrows in Fig. 5C,D,I,J,K), while in neighboring areas sprouts are unusually shortened (arrowheads in Fig. 5C,D,I,J,K). Because of this disparity, the 
distance between the furthest sprouts and the shortest sprouts is very large in these mutants compared with wild-type controls (Fig. 5F,L). The short and long sprouts appear unable to meet, and the resulting vascular front appears to have many "blind ends" compared with the front in wild-type littermates, where a well-connected network forms (Fig. 5, cf. C,D and A,B, and cf. I,J and G,H). Importantly, in the sprouts that grow very far ahead of the advancing plexus, dll4 expression is increased (Fig. 5O), whereas in the "caved" region, dll4 is barely detectable (Fig. 5P), suggesting that this uneven growth front phenotype is caused by imbalanced (unregulated) dl14 expression, consistent with the aforementioned role of Sema3E-Plexin-D1 signaling in Dll4-Notch signaling.

To ablate Plexin-D1 in a temporally controlled manner, we crossed plexin-D1 floxed conditional mice with tamoxifen-inducible Cre-ER mice (Hayashi and McMahon 2002; Zhang et al. 2009). We injected tamoxifen daily from P0 to P2 and analyzed the phenotype at P5. Tamoxifen injection effectively eliminates plexin-D1 mRNA (Supplemental Fig. S9C-E). As shown in Supplemental Figure S9, F-K, postnatal depletion of Plexin-D1 causes defects similar to those observed in constitutive plexin-D1- and sema3E-null mice: an uneven growing front with some areas that sprout far ahead, and neighboring areas that appear to lag far behind.

In addition to the uneven growth front, a decrease in the number of connections was confirmed by counting branch points in control and mutant mice (Fig. 5M,N). A decreased branching phenotype was also previously observed in retinas injected with a synthetic peptide corresponding to the $\delta /$ serrate/Lag-2 domain of Jagl, which can activate Notch (Hellstrom et al. 2007). Elimination of Sema3E-Plexin-D1 signaling by the injection of PlexinD1-Fc results in an increase in Notch activity, thus mimicking Jag-1 injection (Fig. 4D-F). Moreover, this reduced branching phenotype is also consistent with the observed decrease in angpt2-positive tip cells in sema3E mutant mice (Supplemental Fig. S6).

These morphological phenotypes, together with the increased d114 expression observed in the sema3E- and
plexin-D1-null mice, demonstrate that Sema3E-Plexin-D1 signaling is required in vivo for modulating Dll4 and Notch activity and for coordinated vascular growth.

\section{Inhibition of Notch activity in sema3E mutant mice corrects the sema3E phenotype}

If the phenotype observed in the sema3E-null mice is due to a lack of Sema3E-Plexin-D1-mediated feedback inhibition of VEGF activity and downstream Dll4-Notch signaling, we would expect that decreasing Notch activity should rescue the sema3E phenotype. To inhibit Notch activity, we systemically administered the $\gamma$-secretase inhibitor DAPT into sema3E-null mice and their wildtype littermate controls. Retinal vasculature was stained with Isolectin B4 $24 \mathrm{~h}$ after DAPT injection. In wild-type littermate mice, the DAPT-injected retinas showed a dramatic increase in vascular density compared with DMSO-injected retinas (Fig. 6A,B), confirming the previous finding that inhibiting Notch activity results in increasing branching (Hellstrom et al. 2007). DMSOinjected sema3E mutant mice had decreased branching density in the retina, as described previously (Figs. 5N, $6 \mathrm{C})$, and this vascular density defect was restored to nearnormal levels (DMSO-injected wild-type littermate retinas) $24 \mathrm{~h}$ after treatment with DAPT (Fig. 6C-E). These data further support our model (Fig. 7) that Sema3EPlexin-D1 signaling is required as a negative feedback mechanism to regulate Notch activity in order to ensure balanced vascular network formation.

\section{Discussion}

Several families of axon guidance molecules have been demonstrated to also be required for vascular patterning, presumably to direct the developing sprouts via regulation of cytoskeletal dynamics (Carmeliet and Tessier-Lavigne 2005). However, whether they are also involved in other steps of the angiogenic process and their relationship with VEGF is not yet clear. In this study, we found that VEGF can directly control the dynamic expression of Plexin-D1 in endothelial cells and that Sema3E-Plexin-D1 signaling
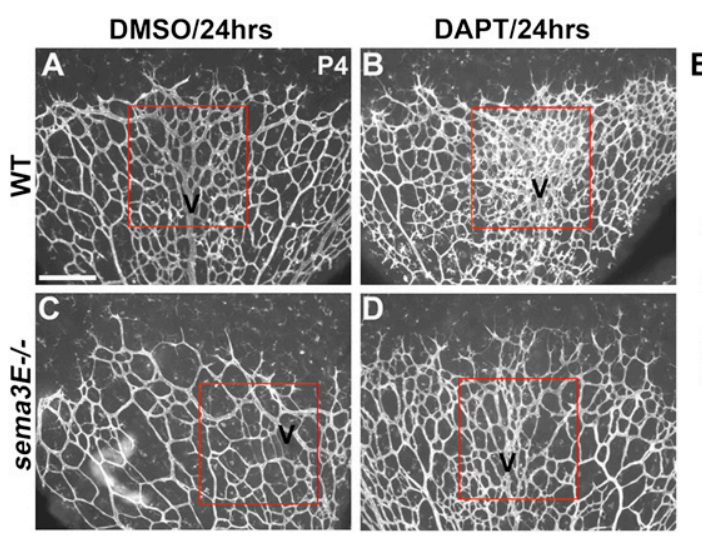

E

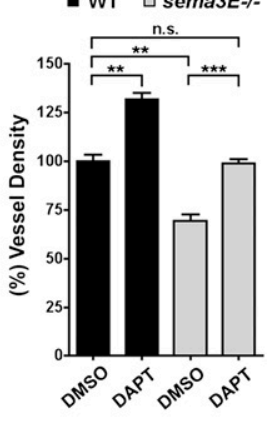

Figure 6. Inhibition of Notch activity restores the vascular phenotype in sema3 $E^{-/-}$mice. $\mathrm{P} 3 \mathrm{sema} 3 E^{-/-}$ mice $(C, D)$ and wild-type littermates $(A, B)$ were systemically injected with either $50 \mathrm{mg} / \mathrm{kg}$ DAPT $(B, D)$ or DMSO $(A, C)$ for $24 \mathrm{~h}$. Retinas were harvested and processed for Isolectin $\mathrm{B} 4$ staining at P4. $(A, B)$ DAPT injection of wild-type littermate retinas caused a hyperdense phenotype $(B)$ compared with DMSO-injected retinas, especially around the veins $(A)$, as has been reported previously. Vein areas are outlined in a box and marked as $\mathrm{V}$ in red. (C) DMSO-injected mutant retinas exhibit significantly less branching $(C)$ compared with wild-type littermates $(A)$, as shown in Figure $5 \mathrm{~N}$. $(D)$ Reduced Notch activity after DAPT treatment restored the vascular density defect in sema $3 E^{-/-}$retinas to near-normal levels $(D)$ compared with the DMSO-treated mutant retina $(C) .(E)$ Quantification of vessel density in P4 retinas. (n.s.) Not significant; $\left({ }^{* *}\right) P<0.01 ;\left({ }^{* * *}\right)$ $P<0.001$. All conditions, $n=3$. The bar $(200 \mu \mathrm{m})$ in $A$ applies to $B-D$. 


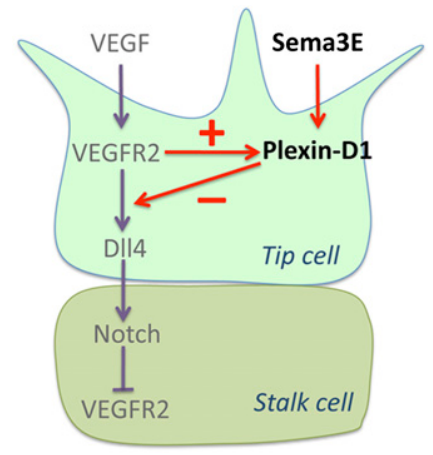

Figure 7. Model for Sema3E-Plexin-D1 function in modulating Dll4-Notch signaling via a VEGF-induced negative feedback mechanism. VEGF induces Plexin-D1 expression (Fig. 2), leading to Plexin-D1 accumulation in tip cells. Sema3E-Plexin-D1 signaling then starts to down-regulate VEGF activity by modulating VEGF-induced Dll4 expression in tip cells (Figs. 3, 4) and, subsequently, Notch activity in stalk cells (Fig. 4D-F). In stalk cells, Notch activity controls the level of VEGFR2 (Lobov et al. 2007).

in turn negatively regulates VEGF-induced Dll4-Notch signaling, a key lateral inhibition pathway that controls the ratio of endothelial tip cells and stalk cells. Sema3EPlexin-D1 gain of function suppresses Dll4 expression, whereas loss of function of Sema3E-Plexin-D1 induces Dll4 expression and Notch activity, and subsequently decreases tip cell formation. As a result, a lack of either Sema3E or Plexin-D1 in mice disrupts the pattern of retinal vascular sprouting and leads to an uneven growing front and a less-branched network, which can be restored by lowering Notch activity in the mutant mice. Therefore, our results suggest that Sema3E-Plexin-D1 functions to modulate the balance between tip and stalk cells through a VEGF-induced negative feedback mechanism.

Vascular networks are uniquely patterned to suit the specific metabolic needs of the tissues in which they reside. We found that in the developing mouse retina, VEGF, Plexin-D1, and Sema3E are expressed by three distinct cell types that are in close proximity to each other (Fig. 1M). Sema3E is expressed in the RGC layer, which forms during early embryonic development (Cepko et al. 1996); VEGF is expressed in astrocytes, which are generated right before birth (Provis et al. 1997; Fruttiger 2007); and Plexin-D1 is expressed in the most superficial vascular layer, which forms right after birth. The proximal expression of Sema3E, Plexin-D1, and VEGF set a platform to allow signals from neural tissues to continuously control the topology of the retina vascular network. For example, the location where Plexin-D1 is most highly expressed is also where the strongest VEGF expression is seen (Fig. $1 \mathrm{E}, \mathrm{F})$. Similarly, as vessels mature, Plexin-D1 expression is lost from arteries and other mature vessels (Fig. 1C) but remains strong in the veins, paralleling the persistence of VEGF expression in the astrocytes near veins but not arteries (Gerhardt et al. 2003). When this communication between vascular and neuronal tissues is disrupted in mice lacking sema3E or plexin-D1, the topology of the retinal vascular network is also changed. Importantly, no detect- able changes were found in either VEGF-A localization or astrocyte distribution in sema3E mutant mice (Supplemental Figs. S10, S11), further indicating that the morphological changes of the vascular network observed in the mutant mice are due to a loss of Sema3E-Plexin-D1 signaling in the endothelial cells. Therefore, the proximal expression of VEGF, Sema3E, and Plexin-D1, together with the reciprocal signaling we discovered between VEGF and Sema3E-Plexin-D1, identifies a novel mechanism through which neuronal tissues regulate the topology of the resident vascular network.

The tightly controlled spatial and temporal distribution of guidance cues in the environment plays an important role in directing growing axons and vessels to form precise networks (Carmeliet and Tessier-Lavigne 2005). Our data support a new mechanism in which expression of the ligand (Sema3E) in the environment is relatively constant, whereas the expression of the receptor (Plexin-D1) is temporally and spatially controlled by VEGF. In addition, activation of receptors by graded ligands typically leads to cytoskeletal changes to direct cell sprouting, whereas we showed that activation of Plexin-D1 by Sema3E modulates VEGF-mediated Dll4-Notch signaling. Consistent with this idea, the phenotype we observe in the retina is very different from the phenotype that we previously described in the intersomitic region (Gu et al. 2005). In the case of intersomitic vessel patterning, Sema3E is expressed in a caudal-to-rostral gradient in the somite, and this gradient serves to prevent intersomitic vessels from entering the caudal region. As a result, exuberant vascular sprouting is observed entering the caudal somite region in both Sema3E and Plexin-D1 mutants. However, in the retina, Sema3E is expressed uniformly by the RGCs and does not appear to form a gradient along the central-to-peripheral axis (Fig. 1G-I). The expression of its receptor, Plexin-D1, on the other hand, is tightly controlled by the VEGF gradient generated by the adjacent astrocyte layer. As a result, instead of overall exuberant vascular sprouting, mutants display uneven sprouting at the growing vessel front and a less developed capillary network, a phenotype that is consistent with our gain-of-function and loss-offunction data on the effect of Sema3E and Plexin-D1 signaling in regulating Dll4 and Notch activity (Figs. 3, 4, 6). Although it is surprising that Sema3E-Plexin-D1 signaling modulates VEGF-induced angiogenesis via Dll4-Notch, the phenotypes we described are consistent with previous studies. For example, a reduced level of dll4 has been shown to lead to an increased number of tip cells and branching (Hellstrom et al. 2007; Suchting et al. 2007). In our study, sema3E mutant mice had increased levels of $d 114$, leading to a decreased number of tip cells and a significant reduction of branching.

Thus, our results suggest a novel role for the guidance ligand-receptor pair Sema3E-Plexin-D1 as a negative feedback signal that modulates VEGF-mediated angiogenic fate determination. Interestingly, recent work has demonstrated that the tip cell and stalk cell assignment is transient, and a constant shuffling of tip and stalk cell positions during angiogenic sprouting was observed (Jakobsson et al. 2010). VEGF promotes the formation of 
the tip cells via Dll4-Notch-mediated lateral inhibition, so we hypothesize that this signaling must be attenuated when a tip cell switches to a stalk cell. Interestingly, VEGF induction of Dll4 was detected earlier than VEGF induction of Plexin-D1 (cf. Supplemental Fig. S12 and Fig. $2 \mathrm{G}-\mathrm{J})$. Thus, it is reasonable to postulate that the VEGFinduced Sema3E-Plexin-D1 negative feedback mechanism described here could promote this tip-stalk switching. For example, VEGF first selects a tip cell by inducing Dll4 expression; as this tip cell extends its filopodia toward higher VEGF concentrations, Plexin-D1 expression is increased. This resulting increase in Sema3EPlexin-D1 signaling then decreases Dll4 expression and the Notch-mediated repression on neighboring cells is relieved. Because the relative expression levels of Dll4 in neighboring cells determine their role as tip or stalk cells, this drop in Dll4 causes the current tip cell to lose its competitive position over its neighbor and it becomes a stalk cell. Thus, we predict that in sema3E and plexinD1 mutant mice, a given tip cell would occupy the tip cell position longer than in control mice.

It has been suggested that $d 114$ heterozygous mutant mice have excessive formation of tip cells, which then leads to an oversprouting phenotype (Hellstrom et al. 2007; Lobov et al. 2007; Suchting et al. 2007; Benedito et al. 2009). However, the endothelial cells located in the caved region in plexin-D1-null and sema3E-null mice did not exhibit an oversprouting phenotype despite the lack of dll4 expression (Fig. 3). Interestingly, dll4, plexin-D1, and several known tip cell markers including $p d g f-b$ and angpt2 were not detectable in endothelial cells in the caved region (Supplemental Fig. S13). In addition, these endothelial cells did not have any protrusion or apparent filopodia formation as expected for tip cell morphology (arrows in Supplemental Fig. S13). Staining for the proliferation marker phospho-Histone $\mathrm{H} 3$ did not show any proliferation in this region (data not shown). Therefore, it is possible that due to the presumed long switching time of cells in plexin-D1 and sema3E mutant mice, as described in the model above, the cells in the caved region are in a "quiescent" state.

Finally, because Plexin-D1 is widely expressed in actively sprouting blood vessels during early development, re-expressed in newly formed vessels during wound healing, and expressed in tumors /Casazza et al. 2010), the negative feedback mechanism described in this study could represent a general mechanism involved in angiogenesis. Moreover, this work suggests that Sema3EPlexin-D1 signaling may be a potential target for the development of therapeutic strategies to treat pathologic angiogenesis, including cancer and diabetic retinopathy, either alone or combined with anti-VEGF therapy.

\section{Materials and methods}

Mice

plexin-D $1^{\text {flox/flox }}$ mice (Zhang et al. 2009) were maintained on a C57Bl/6 background. CAGGCre-ER mice (Hayashi and McMahon 2002) and sema3E $E^{+-}(\mathrm{Gu}$ et al. 2005) mice were maintained on a 129P3J;C57Bl/6 mixed background. plexin-D $1^{+/-}$ mice (Gu et al. 2005) were maintained on an outbred Swiss Webster background. Genomic deletion of plexin-D1 in CAGGCre-ER/ ${ }^{+}$; plexin- $D 1^{\text {flox } /-}$ pups was induced by intraperitoneal injection of tamoxifen (T5648, Sigma-Aldrich) dissolved in safflower oil. Ten micrograms of tamoxifen was injected daily between P0 and P2. Littermate control mice were also injected with the same amount of tamoxifen. Mice were sacrificed at P5 and retinas were isolated for analysis. Swiss Webster and C57Bl/6 wild-type mice were obtained from Taconic Farms, Inc. All animals were treated according to institutional and NIH guidelines approved by the Institutional Animal Care and Use Committee at Harvard Medical School.

\section{Immunohistochemistry of whole-mount retinas}

Eyes were removed and prefixed in $4 \%$ paraformaldehyde (PFA) for $20 \mathrm{~min}$ at room temperature. Retinas were dissected in PBS and then post-fixed in $4 \%$ PFA overnight at $4{ }^{\circ} \mathrm{C}$. Retinas were then permeabilized in PBS, $1 \%$ BSA, and $0.5 \%$ Triton X-100 at $4^{\circ} \mathrm{C}$ overnight; washed twice in PBlec (PBS at pH 6.8, $1 \%$ Triton $\mathrm{X}-100,0.1 \mathrm{mM} \mathrm{CaCl} 2,0.1 \mathrm{mM} \mathrm{MgCl} 2,0.1 \mathrm{mM} \mathrm{MnCl}_{2}$ ); and incubated in Isolectin B4 (1:500; I21411, Molecular Probes) in PBlec overnight at $4^{\circ} \mathrm{C}$. After washing in PBS and a brief postfixation in PFA, the retinas were flat-mounted using ProLong Gold/DAPI anti-fade reagent (P36935, Molecular Probes). Retinas from TNR GFP pups were prepared as described above except that retinas were fixed in $4 \%$ PFA for $2 \mathrm{~h}$ at $4^{\circ} \mathrm{C}$. Retinas were then permeabilized in PBS, $0.5 \%$ Triton X-100, and $1 \%$ normal goat serum overnight at $4^{\circ} \mathrm{C}$; blocked in blocking buffer (PBS, $0.5 \%$ Triton $\mathrm{X}-100,10 \%$ normal goat serum) for $1 \mathrm{~h}$ at room temperature; and incubated with primary antibody $(\alpha$-GFAP $[1$ : 25; DAKO], $\alpha$-GFP [1:500; GFP-1020, Aves Laboratories, Inc.], and $\alpha$-PECAM [1:500; 553370, BD Pharmingen]) in blocking buffer overnight at $4^{\circ} \mathrm{C}$. After washing in PBS $/ 0.5 \%$ Triton X-100 for 2-3 h, retinas were incubated in Alexa Fluor-conjugated secondary antibody, then washed several times and flatmounted. Flat-mounted retinas were analyzed by fluorescence microscopy using a Nikon Eclipse 80i microscope equipped with a Nikon DS-2 digital camera or by confocal laser-scanning microscopy using a Zeiss LSM 510 META. Images were processed using Adobe Photoshop and Image J (National Institutes of Health).

\section{ISH of whole-mount retinas and sections}

Retinas were prepared as described above except that all reagents were pretreated with DEPC and samples were kept in $100 \% \mathrm{MeOH}$ at $-20^{\circ} \mathrm{C}$ until further use. Retinas were progressively rehydrated and washed in PBST (PBS/0.1\% Tween20 ), and then treated with $10 \mu \mathrm{g} / \mathrm{mL}$ proteinase K/PBST for 20 min and post-fixed for $20 \mathrm{~min}$ in $4 \% \mathrm{PFA} / 0.1 \%$ glutaraldehyde in PBST. After washing in PBST, retinas were incubated with hybridization mix $150 \%$ formamide, $1.3 \times$ SSC, 5 mM EDTA, 50 $\mu \mathrm{g} / \mathrm{mL}$ yeast RNA, $0.2 \%$ Tween $-20,100 \mu \mathrm{g} / \mathrm{mL}$ heparin, $0.5 \%$ CHAPS) for $1 \mathrm{~h}$ at $65^{\circ} \mathrm{C}$ and then incubated overnight in hybridization mix containing probe at $65^{\circ} \mathrm{C}$. The following day, retinas were extensively washed with hybridization mix and MABT (100 mM maleic acid, $150 \mathrm{mM} \mathrm{NaCl}_{2}, 1 \%$ Tween-20 at $\mathrm{pH} 7.5$, and then blocked for $1 \mathrm{~h}$ in MABT/10\% heatinactivated sheep serum at room temperature. The retinas were then incubated overnight at $4^{\circ} \mathrm{C}$ with blocking buffer containing anti-digoxigenin-AP antibody (1:1000; Roche). Retinas were then washed in MABT for $24 \mathrm{~h}$, rinsed in fresh NTMT $100 \mathrm{mM}$ $\mathrm{NaCl}_{2}, 100 \mathrm{mM}$ Tris- $\mathrm{HCl}$ at $\mathrm{pH} 9.5,50 \mathrm{mM} \mathrm{MgCl}_{2}, 0.1 \%$ Tween-20), and developed with Nitro-Blue tetrazolium chloride 
and 5-bromo-4-chloro-3'-indolyphosphate p-toluidine salt (Roche) in NTMT at room temperature. Vessels were visualized with Isolectin B4 directly conjugated to Alexa Fluor 488. Images were processed as described above.

ISH was performed on sections cut through the retina using standard methods (Gu et al. 2005). Briefly, frozen retinas were cut in $14-\mu \mathrm{m}$-thick sections using a cryostat (Leica), post-fixed in $4 \%$ PFA, acetylated in $1 \%$ triethanolamine and $0.25 \%$ acetic anhydride, prehybridized, then hybridized with a probe overnight at $65^{\circ} \mathrm{C}$. After hybridization, sections were washed and incubated with AP-conjugated sheep anti-DIG antibody for $90 \mathrm{~min}$ at room temperature. After three washes, sections were incubated in BM Purple (Roche) until positive staining was seen. Digoxigeninlabeled in situ riboprobes were generated by in vitro transcription method (Promega and Roche). The following in situ probes were used: plexin-D1 (NM_026376.3, nt381-1334); sema3E (Gu et al. 2005); GFAP and vegf (provided by Dr. Patricia D'Amore, Schepens Eye Research Institute, MA); brn3b and PDGF-B (provided by Dr. Constance Cepko, Harvard Medical School, MA); angpt2 (provided by Dr. Anne Eichmann, Yale School of Medicine, $\mathrm{CT}$ ); and $d 114$ (provided by Dr. Holger Gerhardt, London Research Institute, London, UK).

\section{Ligand preparation}

To generate AP-tagged Sema3E, Sema3A, or Plexin-D1-Fc, DNA constructs were transfected into HEK 293T cells (American Type Culture Collection) using Lipofectamine 2000 (Invitrogen) and cultured in DMEM containing $10 \%$ fetal bovine serum (FBS, Sigma) for $2 \mathrm{~d}$ or OPTI-MEM (Invitrogen) for $3 \mathrm{~d}$. The conditioned medium prepared in OPTI-MEM was harvested and concentrated using Amicon Ultra centrifugal filters (Ultracel 30K, Millipore). AP-Sema3E and Plexin-D1-Fc constructs were obtained from Dr. Fanny Mann (University of Mediterranee, France) and Dr. Akiyoshi Uemura (RIKEN), respectively. To generate the APPlexin-D1 construct, the extracellular domain of Plexin-D1 from Plexin-D1-Fc was cloned into the pAP-Tag5 vector.

\section{In vitro ligand-receptor-binding assay}

One milliliter each of $0.4 \mathrm{nM}$ AP-Sema3A, AP-Sema3E, APPlexin-D1 conditioned media generated in DMEM containing $10 \%$ FBS was mixed with $0.5 \mathrm{~mL}$ of Plexin-D1-Fc conditioned media and incubated overnight at $4^{\circ} \mathrm{C}$. The next day, $10 \mu \mathrm{L}$ of immobilize protein $\mathrm{A} / \mathrm{G}$ resin (Pierce) was added to the ligandreceptor mixture and incubated one more day at $4^{\circ} \mathrm{C}$. Then, unbound proteins in the mixture were removed by centrifugation at $5000 \mathrm{rpm}$ for $5 \mathrm{~min}$ at $4^{\circ} \mathrm{C}$ and bound complexes were further washed in $1 \mathrm{~mL}$ of immunoprecipitation buffer (IP buffer: $50 \mathrm{mM}$ Tris- $\mathrm{HCl}$ at $\mathrm{pH} 8.0,1 \%$ Nonidet P-40, $150 \mathrm{mM} \mathrm{NaCl}$, $2 \mathrm{mM}$ EDTA, $0.3 \mathrm{mM}$ aprotinin, $10 \mathrm{mM}$ leupeptin, $0.5 \mathrm{mM}$ phenylmethylsulfonyl fluoride). Following several washes in IP buffer, proteins were eluted in Laemmli sample buffer and then heated for $5 \mathrm{~min}$ at $100^{\circ} \mathrm{C}$. A half volume of eluted proteins was used for standard Western blotting (Gu et al. 2002). Sheep antiplacental AP antibody (13-2355, American Research Product) and horseradish peroxidase-conjugated goat anti-sheep IgG antibodies were used to probe AP-conjugated ligand proteins

\section{Intraocular injections}

One microliter of $1 \mu \mathrm{g} / \mu \mathrm{L}$ VEGF (National Cancer InstituteFrederick), VEGFR2 neutralizing antibody (AF644, R\&D Systems), PBS, 100 nM AP, 100 nM AP-Sema3E, or $0.2 \mu \mathrm{g} / \mu \mathrm{L}$ Plexin-D1-Fc was injected into the eyes of anesthetized P4 or P5 mice using a 10- $\mu \mathrm{L}$ microinjection pipette (Drummond) equipped with a man- ually pulled glass pipette. Mice were sacrificed and retinas were isolated for either whole-mount ISH or immunohistochemistry.

\section{DAPT and Jag1 treatments}

$\gamma$-Secretase inhibitor DAPT (Sigma D5942; dissolved in DMSO) or vehicle alone (DMSO) was administered subcutaneously at 50 $\mathrm{mg} / \mathrm{kg}$ per mouse into either wild-type littermates or sema3 $E^{-/-}$ pups at P3. Twenty-four hours later (P4), retinas were dissected and processed for Isolectin B4 staining. Quantification of vessel density was performed by counting branch points per 100 $\mu \mathrm{m}^{2}$ on images taken at $10 \times$ magnification. Jag- 1 peptide (CDDYYYGFGCNKFCRPR) and scrambled peptide for Jag1 (scJag-1) (RCGPDCFDNYGRYKYCF) were purchased from GenScript USA, Inc. Peptides were prepared and injected as previously reported (Hellstrom et al. 2007). Briefly, peptides were dissolved in $50 \%$ DMSO and $50 \% \mathrm{H}_{2} \mathrm{O}$ at a $10 \mathrm{mg} / \mathrm{mL}$ concentration. Twenty-five microliters of stock solution was subcutaneously injected once. One hour after peptide injection, animals were subjected to intraocular injection for AP or AP-Sema3E. Five hours later, retinas were dissected and processed for plexinD1 ISH followed by Isolectin B4 staining.

\section{Cell culture and quantitative RT-PCR}

HUVECs (cc-2517, Lonza) were maintained in endothelial cell basal medium-2 (EBM-2, CC-3156, Lonza) supplemented with EGM-2 growth factor mixture (CC-4176, Lonza). For siRNA knockdown, cells were transfected with plexin-D1 siRNA (M-014121-01, Dharmacon) by reverse transfection according to the manufacturer's protocol. Nontransfected or transfected HUVECs were plated in six-well plates and allowed to recover overnight. On the second day, cells were starved overnight by replacing with plain EBM-2 medium without growth factor supplements. Wild-type or plexin-D1 RNAi transfected HUVECs were treated with VEGF (50 ng/mL in EBM) or VEGF plus Sema3E (50 ng/mL VEGF plus $2 \mathrm{nM}$ Sema3E in EBM) for 30 min, with nontreated cells serving as the control. The total RNA was extracted using TRIzol (Invitrogen) according to the manufacturer's instructions. cDNAs were generated from $2.5 \mu \mathrm{g}$ of total RNA using Reverse Transcript kit (Invitrogen). Two microliters of the synthesized cDNA was used for quantitative PCR using SYBR Advantage qPCR mix (639676, Clontech). PCR was carried out using an MJ Research PTC-200 Thermo Cycler. Gene expression was normalized to the endogenous control GAPDH.

The following primers were used for PCR: Dll4 (forward, 5'-CTGGGGAGGCCTGTTTTGTG-3'; reverse, 5'-GCAGTTG GAGCCGGTGAAGT-3') and GAPDH (forward, 5'-TGCACCA CCAACTGCTTAGC-3' ${ }^{\prime}$; reverse, 5'-GGCATGGACTGTGGTC ATGAG-3').

\section{Analysis of postnatal retinal angiogenesis}

Images of whole-mount retinas were taken at $4 \times$ magnification to measure vascular expansion and $10 \times$ magnification to measure vessel density. The number of branch points per field $(100 \times$ $100-\mu \mathrm{m}$ fields, images taken with $10 \times$ magnification, $15-20$ fields, four to five retinas per group) at the periphery of vasculature was quantified using Image J. The distance from the optic nerve was measured from the average length of four lines per retina drawn from the optic nerve to the edge of the vasculature or retina. The unevenness of the vessel front was measured by subtracting the shortest radius from the longest radius within the retina. Twenty-four to 32 fields from six to eight retinas per group were quantified. To quantify the percentage of Isolectin B4-positive vessels expressing the gene of interest, areas with 
a positive in situ signal were measured and normalized to total blood vessel area using Image J. All quantitative data were compiled and analyzed using unpaired two-tailed Student's $t$-test unless otherwise noted.

\section{Acknowledgments}

We thank Alex Kolodkin, Pat D'Amore, David Ginty, Michael Greenberg, Chuck Weitz, Qiufu Ma, Lisa Goodrich, Bob Datta, Christiana Ruhrberg, Masha Gelfand, and Ayal Ben-Zvi for helpful comments on the manuscript; Andrew McMahon for providing CAGGCre-ERTM mice; Fanny Mann for providing Sema3E $E^{+/-}$mice; Pat D'Amore for providing VEGF in situ probe and protocol; Connie Cepko for providing in situ probe for PDGF-B and Brn3b; Holger Gerhard for providing protocols for whole-mount in situ and in situ probes for Dll4; Anne Eichmann for providing Angpt2 in situ probe; National CancerInstituteFrederick for providing VEGF; Optical Imaging Program at Harvard NeuroDiscovery Center for helping with confocal images; and Kyle Deerwester and Daniel Levenstein for helping with quantification. This work was supported by NRSA Postdoctoral training grant T32 NS07484-12 (to J.K.), the Lefler postdoctoral fellowship (to W.O.), NIH grant RO1NS065048 (to Y.Y.), and the following grants to C.G.: Sloan research fellowship, March of Dimes Basil O'Connor award, Loreen Arbus Fellowship, and NIH grant RO1NS064583.

\section{References}

Adams RH, Eichmann A. 2010. Axon guidance molecules in vascular patterning. Cold Spring Harb Perspect Biol 2: a001875. doi: 10.1101/cshperspect.a001875.

Benedito R, Roca C, Sorensen I, Adams S, Gossler A, Fruttiger M, Adams RH. 2009. The notch ligands Dll4 and Jagged1 have opposing effects on angiogenesis. Cell 137: 11241135.

Carmeliet P, Tessier-Lavigne M. 2005. Common mechanisms of nerve and blood vessel wiring. Nature 436: 193-200.

Casazza A, Finisguerra V, Capparuccia L, Camperi A, Swiercz JM, Rizzolio S, Rolny C, Christensen C, Bertotti A, Sarotto I, et al. 2010. Sema3E-Plexin D1 signaling drives human cancer cell invasiveness and metastatic spreading in mice. J Clin Invest 120: 2684-2698.

Cepko CL, Austin CP, Yang X, Alexiades M, Ezzeddine D. 1996. Cell fate determination in the vertebrate retina. Proc Natl Acad Sci 93: 589-595.

Chauvet S, Cohen S, Yoshida Y, Fekrane L, Livet J, Gayet O, Segu L, Buhot MC, Jessell TM, Henderson CE, et al. 2007. Gating of Sema3E/PlexinD1 signaling by neuropilin-1 switches axonal repulsion to attraction during brain development. Neuron 56: 807-822.

Connolly SE, Hores TA, Smith LE, D'Amore PA. 1988. Characterization of vascular development in the mouse retina. Microvasc Res 36: 275-290.

del Toro R, Prahst C, Mathivet T, Siegfried G, Kaminker JS, Larrivee B, Breant C, Duarte A, Takakura N, Fukamizu A, et al. 2010. Identification and functional analysis of endothelial tip cell-enriched genes. Blood 116: 4025-4033.

De Smet F, Segura I, De Bock K, Hohensinner PJ, Carmeliet P. 2009. Mechanisms of vessel branching: filopodia on endothelial tip cells lead the way. Arterioscler Thromb Vasc Biol 29: 639-649.

Dorrell MI, Aguilar E, Friedlander M. 2002. Retinal vascular development is mediated by endothelial filopodia, a preexisting astrocytic template and specific R-cadherin adhesion. Invest Ophthalmol Vis Sci 43: 3500-3510.
Duncan AW, Rattis FM, DiMascio LN, Congdon KL, Pazianos G, Zhao C, Yoon K, Cook JM, Willert K, Gaiano N, et al. 2005. Integration of Notch and Wnt signaling in hematopoietic stem cell maintenance. Nat Immunol 6: 314-322.

Eilken HM, Adams RH. 2010. Dynamics of endothelial cell behavior in sprouting angiogenesis. Curr Opin Cell Biol 22: 617-625.

Fruttiger M. 2007. Development of the retinal vasculature. Angiogenesis 10: 77-88.

Gelfand MV, Hong S, Gu C. 2009. Guidance from above: common cues direct distinct signaling outcomes in vascular and neural patterning. Trends Cell Biol 19: 99-110.

Gerhardt H. 2008. VEGF and endothelial guidance in angiogenic sprouting. Organogenesis 4: 241-246.

Gerhardt H, Golding M, Fruttiger M, Ruhrberg C, Lundkvist A, Abramsson A, Jeltsch M, Mitchell C, Alitalo K, Shima D, et al. 2003. VEGF guides angiogenic sprouting utilizing endothelial tip cell filopodia. J Cell Biol 161: 1163-1177.

Gitler AD, Lu MM, Epstein JA. 2004. PlexinD1 and semaphorin signaling are required in endothelial cells for cardiovascular development. Dev Cell 7: 107-116.

Gu C, Limberg BJ, Whitaker GB, Perman B, Leahy DJ, Rosenbaum JS, Ginty DD, Kolodkin AL. 2002. Characterization of neuropilin-1 structural features that confer binding to semaphorin 3A and vascular endothelial growth factor 165 . J Biol Chem 277: 18069-18076.

Gu C, Yoshida Y, Livet J, Reimert DV, Mann F, Merte J, Henderson CE, Jessell TM, Kolodkin AL, Ginty DD. 2005. Semaphorin $3 \mathrm{E}$ and plexin-D1 control vascular pattern independently of neuropilins. Science 307: 265-268.

Hayashi S, McMahon AP. 2002. Efficient recombination in diverse tissues by a tamoxifen-inducible form of Cre: a tool for temporally regulated gene activation/inactivation in the mouse. Dev Biol 244: 305-318.

Hellstrom M, Phng LK, Hofmann JJ, Wallgard E, Coultas L, Lindblom P, Alva J, Nilsson AK, Karlsson L, Gaiano N, et al. 2007. Dll4 signalling through Notch1 regulates formation of tip cells during angiogenesis. Nature 445: 776-780.

Jakobsson L, Franco CA, Bentley K, Collins RT, Ponsioen B, Aspalter IM, Rosewell I, Busse M, Thurston G, Medvinsky A, et al. 2010. Endothelial cells dynamically compete for the tip cell position during angiogenic sprouting. Nat Cell Biol 12: 943-953.

Leslie JD, Ariza-McNaughton L, Bermange AL, McAdow R, Johnson SL, Lewis J. 2007. Endothelial signalling by the Notch ligand Delta-like 4 restricts angiogenesis. Development 134: 839-844.

Lobov IB, Renard RA, Papadopoulos N, Gale NW, Thurston G, Yancopoulos GD, Wiegand SJ. 2007. Delta-like ligand 4 (Dll4) is induced by VEGF as a negative regulator of angiogenic sprouting. Proc Natl Acad Sci 104: 3219-3224.

Phng LK, Gerhardt H. 2009. Angiogenesis: a team effort coordinated by notch. Dev Cell 16: 196-208.

Provis JM, Leech J, Diaz CM, Penfold PL, Stone J, Keshet E. 1997. Development of the human retinal vasculature: cellular relations and VEGF expression. Exp Eye Res 65: $555-568$.

Risau W. 1997. Mechanisms of angiogenesis. Nature 386: 671674.

Roca C, Adams RH. 2007. Regulation of vascular morphogenesis by Notch signaling. Genes Dev 21: 2511-2524.

Ruhrberg C, Gerhardt H, Golding M, Watson R, Ioannidou S, Fujisawa H, Betsholtz C, Shima DT. 2002. Spatially restricted patterning cues provided by heparin-binding VEGFA control blood vessel branching morphogenesis. Genes Dev 16: $2684-2698$. 
Stone J, Chan-Ling T, Pe'er J, Itin A, Gnessin H, Keshet E. 1996. Roles of vascular endothelial growth factor and astrocyte degeneration in the genesis of retinopathy of prematurity. Invest Ophthalmol Vis Sci 37: 290-299.

Strasser GA, Kaminker JS, Tessier-Lavigne M. 2010. Microarray analysis of retinal endothelial tip cells identifies CXCR4 as a mediator of tip cell morphology and branching. Blood 115: 5102-5110.

Suchting S, Freitas C, le Noble F, Benedito R, Breant C, Duarte A, Eichmann A. 2007. The Notch ligand Delta-like 4 negatively regulates endothelial tip cell formation and vessel branching. Proc Natl Acad Sci 104: 3225-3230.

Thurston G, Kitajewski J. 2008. VEGF and Delta-Notch: interacting signalling pathways in tumour angiogenesis. $\mathrm{Br} I$ Cancer 99: 1204-1209.

Torres-Vazquez J, Gitler AD, Fraser SD, Berk JD, Pham VN, Fishman MC, Childs S, Epstein JA, Weinstein BM. 2004. Semaphorin-plexin signaling guides patterning of the developing vasculature. Dev Cell 7: 117-123.

Uemura A, Kusuhara S, Katsuta H, Nishikawa S. 2006. Angiogenesis in the mouse retina: a model system for experimental manipulation. Exp Cell Res 312: 676-683.

Weidemann A, Krohne TU, Aguilar E, Kurihara T, Takeda N, Dorrell MI, Simon MC, Haase VH, Friedlander M, Johnson RS. 2010. Astrocyte hypoxic response is essential for pathological but not developmental angiogenesis of the retina. Glia 58: 1177-1185.

Zhang Y, Singh MK, Degenhardt KR, Lu MM, Bennett J, Yoshida Y, Epstein JA. 2009. Tie2Cre-mediated inactivation of plexinD1 results in congenital heart, vascular and skeletal defects. DeV Biol 325: 82-93. 


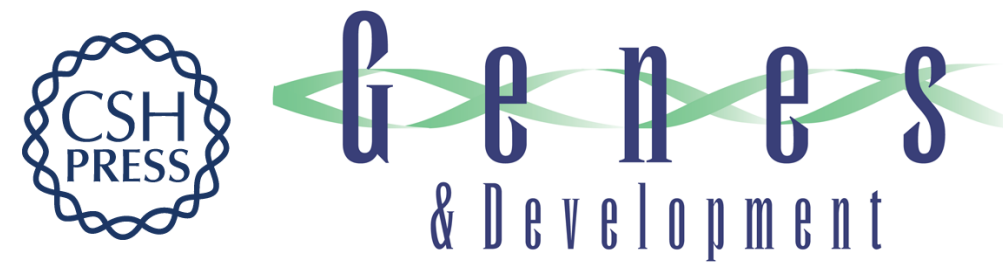

\section{Semaphorin 3E-Plexin-D1 signaling regulates VEGF function in developmental angiogenesis via a feedback mechanism}

Jiha Kim, Won-Jong Oh, Nicholas Gaiano, et al.

Genes Dev. 2011, 25:

Access the most recent version at doi:10.1101/gad.2042011

Supplemental http://genesdev.cshlp.org/content/suppl/2011/07/01/25.13.1399.DC1
Material

References This article cites 37 articles, 15 of which can be accessed free at:

http://genesdev.cshlp.org/content/25/13/1399.full.html\#ref-list-1

License

Email Alerting

Receive free email alerts when new articles cite this article - sign up in the box at the top

Service

right corner of the article or click here.

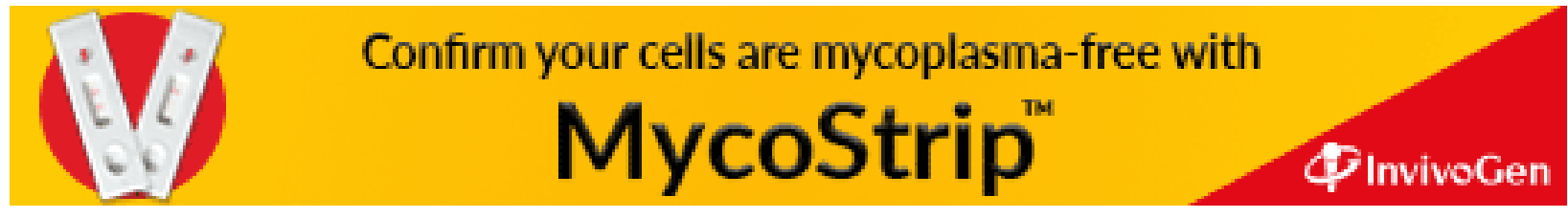

